\title{
Review
}

\section{How culture shapes social cognition deficits in mental disorders - A review}

- Culture \& social cognition in psychiatry -

Katja Koelkebeck $^{1 *}$, Teruhisa Uwatoko ${ }^{2,3}$, Jiro Tanaka ${ }^{4,5}$, Mariska Esther Kret $^{6}$

${ }^{1}$ Department of Psychiatry and Psychotherapy, School of Medicine, University of Muenster, Muenster, Germany

${ }^{2}$ Department of Psychiatry, Graduate School of Medicine, Kyoto University, 54 Shogoinkawaharacho, Sakyo-ku, Kyoto 606-8507, Japan, Tel.: +81-75-751-3386; Email: uwatoko.teruhisa.8s@kyoto-u.ac.jp

${ }^{3}$ Kyoto University Health Service, Yoshidahonmachi, Sakyo-ku, Kyoto 606-8501, Japan, Tel.: +81-75-753-2416

${ }^{4}$ Santa Monica College, Faculty of Modern Languages and Cultures, 1900 Pico Boulevard Santa Monica, CA 90405, USA, Tel.: 1-310-434-4248; Email: tanaka_jiro@smc.edu

${ }^{5}$ Los Angeles Valley College, Adjunct Faculty in Foreign Languages, 5800 Fulton Ave. Valley Glen, CA 91401, USA, Tel: 1-818-947-2381

${ }^{6}$ Leiden University, Institute of Psychology, The Cognitive Psychology Unit, Wassenaarseweg 52, 2333 AK Leiden, Tel.: +31-71 527 6359; Email: m.e.kret@fsw.leidenuniv.nl

*corresponding author:

Albert-Schweitzer-Campus 1, Building A9, 48149 Muenster, Germany, Tel.: +49-2518356601, Fax: +49-251-8356612, Email: katja.koelkebeck@uni-muenster.de 


\begin{abstract}
Social cognitive skills are indispensable for successful communication with others. Substantial research has determined deficits in these abilities in patients with mental disorders. In neurobiological development and continuing into adulthood, cross-cultural differences in social cognition have been demonstrated. Moreover, symptomatic patterns in mental disorders may vary according to the cultural background of an individual. Crosscultural studies can thus help in understanding underlying (biological) mechanisms and factors that influence behavior in health and disease. In addition, studies that apply novel paradigms assessing the impact of culture on cognition may benefit and advance neuroscience research. In this review, the authors give an overview of cross-cultural research in the field of social cognition in health and in mental disorders and provide an outlook on future research directions, taking a neuroscience perspective.
\end{abstract}

\title{
Keywords
}

Transcultural studies; neural networks; mental disorders; Theory of Mind; emotion

\section{Word count:}

Body: XX

References: 3.672 


\section{Introduction}

Social cognition plays a major role in an individual's ability to interact with its social environment. According to the definition of Lieberman (2007), social cognition is an umbrella term that usually subsumes concepts of understanding others, understanding oneself, controlling oneself and the processes that occur at the interface between self and others. It covers, for instance, a set of skills that relate to the identification and interpretation of emotions, e.g. in facial expressions (Comparelli et al., 2013), but also to the inference of one's own and other people's mental states, the so-called mentalizing or Theory of Mind (ToM) (Blakemore et al., 2003). Research in clinical populations has shown that some mental disorders present with distinct deficits in social cognitive abilities, for instance affective and psychotic disorders (Hoertnagl \& Hofer, 2014). Psychiatric symptomatology is considered an interplay between diseases, dimensions of personality, goal-directed behaviors and life stories (McHugh \& Slavney, 1993). However, recently not only developmental and socio-cultural factors have been intensively investigated; genetic, brain imaging and behavioral psychiatric research approaches have been joined to create modern research models of neurodevelopmental disorders (Deeley et al., 2014; Ma, Wang et al., 2014). Within this framework, cultural neuroscience approaches have focused on neuroplasticity as a manifestation of socio-cultural impact on the brain. The study of the phenomenology of psychiatric symptoms in different cultural environments might contribute critical information to what is already known about healthy individuals, both in terms of mind and behavior, as well as in terms of how the brain mediates culture-mind interactions in the extremes of normalcy and disease.

This article will provide an outline of cross-cultural differences in social cognition, targeting psychiatric symptomatology in affective and psychotic disorders. To create an understanding for the background of socio-cultural differences and for a better understanding of pathologic states, we will include a brief introductory overview of the data on neurophysiological development and cross-cultural differences in social cognition in healthy individuals. We will then summarize recent neuroscientific approaches in cross-cultural social cognitive research and will link these findings to clinical applications and to future research directions.

\section{Culture and the Brain}

\section{Impact of culture on social cognition}

After learning the basic rudiments of emotion and self/other distinction, children start to acquire social cognitive skills which are impacted strongly by culture (Callaghan et al., 2011). 
The subsequent developmental differences in social cognitive skills relate to more complex abilities such as, e.g., mentalizing (Wellman, Cross, \& Watson, 2001). For instance, North American children have been described to develop an early understanding of the fact that two individuals (with desires) might have differing beliefs (Wellman, Fang, Liu, Zhu, \& Liu, 2006). Chinese children, on the other hand, seem to understand earlier that individuals may be knowledgeable or ignorant of facts and situations, irrespective of their beliefs or desires. Naito and Koyama (2006) found that Japanese children develop false-belief skills later than Western children, but had better skills at interpreting situations, strongly depending on the inference of implicit social information. These differences may be fostered by educational styles, e.g. early social training (see e.g. Hendry, 1986), differential use of mental state terms (Lee, Olson, \& Torrance, 1999; Wellman et al., 2006) and literacy of parents (Li \& Rao, 2000). Kobayashi, Glover \& Temple (2007) suggest that neural correlates of ToM may begin to vary depending upon cultural/linguistic background early in life. In their functional imaging studies employing ToM tasks, several brain regions (inferior frontal gyrus (IFG) and temporo-parietal junction (TPJ)) were employed in a culture- and/or language-dependent manner.

It has been proposed that equal performance levels on social cognitive tasks across cultures are reached in adulthood (Wellman et al., 2001). Also, universality of facial emotional expression recognition (Brandt \& Boucher, 1985) as well as the ability to identify particular emotions (Ekman \& Friesen, 1971; Ekman, Friesen, \& Ellsworth, 1972) has been described. However, cultural variations exist that may relate to different societies' sanctions and appraisals of specific emotional expressions (Markham \& Wang, 1996). Certain societies, for instance the Japanese, may perceive the open expression of emotions as too strong or inappropriate (Aune \& Aune, 1996). Ratings of emotional intensity can accordingly vary across cultures (Ekman et al., 1972; Matsumoto \& Ekman, 1989; Matsumoto et al., 2000). East Asian individuals have also been shown to process emotional face information differently, judging from the fixation patterns in faces of others (Blais et al., 2008), which suggests a biological basis for social cognition performance differences. In non-Asian cultures, a tendency toward a more self-centered (individualistic) perception of one's social surroundings has been substantiated, while Asian cultures are likely to perceive social information in a contextual, inter-personal way (collectivistic) (Triandis, 2001). The tendency of Asian individuals to predominantly interpret the (emotional) contents of a situation may be connected to their group-focused view of personhood (Shweder et al., 1998). This might explain the finding that e.g. Japanese participants make more statements about contextual 
information and relationships than American participants did (Matsuda \& Nisbett, 2001), while North Americans seem to ignore contextual information when making judgments (Kitayama, Duffy, Kawamura, \& Larsen, 2003).

In summary, normal development in social cognition is based on culture-dependent strategies in education, language use and behavior. Although some social cognitive processes are understood to be universal, there are certain cultural variations present that can be traced into adulthood. Biological reaction patters, such as eye-movement in reaction to social stimuli, suggest that cultural variations may impact on cerebral functioning from an early age.

\section{Culture and Mental Disorders}

Humans are a species of primate that has evolved to transmit large amounts of culturally encoded information. It is thus helpful to consider a concept such as "culture" in its evolutionary framework - that is, as a series of adaptations shaped by natural selection. Human mentalizing and intentional thinking may enable not only the copying of behavior, but also the innovation seen in many culturally transmitted tools and practices (Richerson \& Boyd, 2005; Tomasello, 2000). These practices produce and sustain the flexibility that has allowed humans to inhabit a wide range of environments that are much more extensive and include a larger variety of extremes than those inhabited by our closest primate relatives (Richerson \& Boyd, 2005; Tomasello, 2000). Is it possible that mentalism-an ancient adaptation that allowed us to coordinate action in large groups-also makes us prone to detecting intention and meaning all around us? Does it, perhaps, make us prone to psychosis? For a better understanding of psychopathological processes, efforts have been made to describe psychopathological phenomena that are considered to be linked to ethnic-cultural characteristics or social conditions (Jilek, 1995; Yap, 1951). A variety of studies comparing symptom patterns, as for instance in descriptions of possession (Furukawa \& Bourgeois, 1984; Mesulam, 1981), have been published which have since come to be known as comparative ethnopsychiatry or -psychology. Symptom dimensions as functions of the sociocultural background of an individual have been found to be correlating more strongly with underlying neural organization than categorical constructs, such as disorders (van Praag, 1990). When considering the benefits of comparative psychiatry in the understanding of symptom patterns, it should be kept in mind that all societies arbitrarily define deviations in a distinct way and view symptoms and disorders against the background of what is considered to be normal in their culture (Murphy, 1976). Based on the DSM IV criteria, it has been shown that similar psychiatric diagnoses have been made across cultures (Australia, India, 
Malaysia) regarding their form, but where the contents of symptoms, e.g. delusional symptomatology, is concerned, different subgroups need to be considered for specific cultures (McLean et al., 2014).

In the following section we present important findings of symptom pattern variations between cultures for (major) mental disorders, followed by findings on social cognitive differences.

\section{Psychotic Disorders}

While the prevalence of schizophrenia has been shown to maintain a constant rate across cultures, the course of the disorder has been shown to vary (Siegert, 2001). For example, patients with schizophrenia in developing countries seem to recover more quickly (Sass, 1997), with familial inter-dependency posing one protecting factor (Singh, Harley, \& Suhail, 2013). More importantly for the present review, however, recent research has shown that symptom patterns vary according to cultural background (Koelkebeck \& Wilhelm, 2014). In Western patients, religious delusions and delusional guilt (Tateyama et al., 1993; Tateyama, Asai, Hashimoto, Bartels, \& Kasper, 1998), delusions of grandeur (Stompe et al., 1999) as well as of persecution (Minsky, Vega, Miskimen, Gara, \& Escobar, 2003; Tateyama et al., 1998; Veling, Hoek, Selten, \& Susser, 2011) have been shown to occur more frequently than, e.g., in Asian and African cultures. Specific delusional contents can refer to political background (e.g. espionage in South Korea (Kim et al., 2001; Kim et al., 1993)), societal characteristics (e.g. strong will to avoid shame in Japan (Tateyama et al., 1993; Tateyama et al., 1998)), or cultural beliefs (e.g. fox demon possession in Japan (Omata, 1985)). Tactile hallucinations seem to occur frequently in patients from Africa and the Middle East, while in European countries visual hallucinations have been described as being most frequent (Ndetei \& Vadher, 1984). Hallucinations have been found to be more persistent in African countries, while Latin-Americans report more somatic concerns (Bauer et al., 2011). However, cultural effects may not necessarily be delineated by geopolitical boundaries (Gecici et al., 2010) since symptom patterns seem to also depend on present living circumstances, as a study on immigrants to the UK, who hallucinated in English, and not their native language, showed (Suhail \& Cochrane, 2002).

\section{Affective Disorders}

The prevalence of affective disorders varies across countries (Weissman et al., 1996) and there is evidence for culture-specific symptomatology (Kleinman \& Good, 1985). Cultural concepts of loss of control and attributional bias toward the self may impact depressive mood 
differently (Kirmayer \& Groleau, 2001). Again, language may have an effect on the symptom dimensions of depression, as cultures have different idioms of distress (Kirmayer \& Groleau, 2001). For example, individuals from Eastern, collectivistic cultures have been shown to report their symptoms in somatic and interpersonal terms as compared to Westerners, who use affective, existential, cognitive and somatic terminology (Marsella, 1980). Feelings of guilt and self-reproach also seem to vary at different investigation sites with the highest rates in Switzerland and Japan (Jablensky, Sartorius, Gulbinat, \& Ernberg, 1981). In Japan, for instance, individuals are encouraged to attribute failure to themselves and success to the group (DeVos, 1985; Markus \& Kitayama, 1991). In a Europe-wide study, Italian patients scored higher on ratings of hypochondria, motor retardation, hopelessness, loss of interest and dissatisfaction, while Swedish patients suffered from the inability to feel, weight loss, tachycardia and agitation (Perris et al., 1981). In British clinics, patients of African origin presented more often with manic symptoms and Afro-Caribbeans had more moodincongruent symptoms (Kirov \& Murray, 1999).

\section{Culture-bound syndromes}

Culture-bound syndromes are clinical presentation forms of symptoms that are culturally distinctive (Kirmayer, 2001). These syndromes offer insights into disorders which depend strongly on the socio-cultural background of the individual. A classic culture-bound syndrome is koro, which is common in South-east Asia as well as in China (Cheng, 1996). It implies the strong conviction that the male sexual organ is retracted inside the body (Freudenmann \& Schonfeldt-Lecuona, 2005). A similar phenomenon has been described in India, with male patients fearing the loss of power due to the belief of losing their semen through premature ejaculation or from passing semen in their urine (Dhat syndrome (Sumathipala, Siribaddana, \& Bhugra, 2004)). Taijin kyofusho is a phenomenon characterized by excessive nervousness and fear in social situations. While it has been described as a subtype of social anxiety disorder (Kirmayer 1991), it is particularly characterized by the fear to offend or harm others. This type of anxiety has been related to the Japanese culture with its specific value of consideration for others in social situations (Suzuki, Takei, Kawai, Minabe, \& Mori, 2003). Another recently described phenomenon in Japan is hikikomori. It is defined as social withdrawal for more than six months. While it is suggested that hikikomori may be a representation of chronic schizophrenia, as patients sometimes show a strong immersion in personal interests (Teo \& Gaw, 2010), cases with no subjective psychological distress have also been described. In these instances, patients have an apathetic lifestyle with no interest in 
hobbies of any sort (Kondo et al., 2013). Life-long financial dependency seems relatively acceptable in Japan, which is why a strong impact on the development of hikikomori has been proposed. However, recent reports suggest that the so-called modern type depression, which has spread to other countries, is also a form of hikikomori (Kato, Shinfuku, Sartorius, \& Kanba, 2011).

\section{Behavioral Findings}

Little data is available on cross-cultural differences in the perception of social stimuli in patient groups, although abnormalities in self/other perception may form a model for the functioning of culture-based social cognition and vice versa (Fabrega, 1989). It has been shown that emotion recognition disadvantages in schizophrenia are similar across cultures (Lee, Lee, Kweon, Lee, \& Lee, 2010). In contrast, schizophrenia patients of AmericanCaucasian origin have been shown to be more highly skilled at the perception of emotions as compared to samples of African- and Latin-Americans (Brekke, Nakagami, Kee, \& Green, 2005). In a study on American, German and Indian patients with schizophrenia (Habel et al., 2000), Indian patients performed significantly worse than the other groups on an emotion discrimination task using Caucasian faces. A study using both Caucasian- and AfricanAmerican facial stimuli demonstrated that patients with schizophrenia were more likely to recognize same-race than other-race faces (Pinkham et al., 2008). In two studies that assessed social cognition in relation to depressed mood in Greek (Bernieri \& Gillis, 1993) and Northern American (Gillis \& Bernieri, 1993) college students, dyadic interaction videos were presented. College students with depressed symptoms were shown to track female interaction partners to judge interactional contents. In a sample of Asian immigrants to the US, these immigrants tended to focus more strongly on affective components of depression than on somatic components (Chen, Guarnaccia, \& Chung, 2003). Furthermore, the level of selfattention has been identified as a mediator of cultural effects on depression.

To summarize, in mental disorders the main cultural differences are seen in the variation of symptom patterns, but distinct, culture-specific disorders have been described as well. These specific disorders might also be expressions of other mental disorders known in the Western world, for instance anxiety disorders in the case of hikikomori in Japan. Social cognition differences in mental disorders across cultures have rarely been investigated, but the few available studies indicate cultural variation which is more extreme in patient groups, and particularly exaggerated when stimuli with features of non-familiar groups, so-called outgroups, are involved. 


\section{Impact of culture on neuroplasticity}

In recent research on social cognition, neuroimaging methods have been increasingly used to investigate its neuronal basis. While the available data on behavioral performance differences in social cognition in mental disorders are very limited, imaging findings are not available at all. In order to identify areas of research that might be applied to patient groups, we will summarize what has been found in the healthy population. As mentioned above, social cognition is a term that subsumes processes that occur at the interface between self and others (Lieberman, 2007). Since there is very little data available regarding social cognition in a narrow sense, e.g. mentalizing or emotion identification skills, we applied the term "social cognition” in a broader sense, also including cognitive processes of self-/other-concepts, empathy for pain as well as self-referential thoughts.

In healthy individuals, specialized cortical networks have been suggested to mediate social cognitive abilities, including the temporal, medial prefrontal (mPFC) and dorsolateral prefrontal (dlPFC) cortex as well as the amygdalae (Castelli, Happé, Frith, \& Frith, 2000; Voellm et al., 2006). Cross-cultural differences in the mode and development of social cognitive abilities suggest that the brain might be activated in a culture-specific manner in response to social cognitive cues. Research focusing on the investigation of Caucasian and Asian groups in functional magnetic resonance imaging (fMRI) has created several hypotheses regarding possible activation differences across cultures. Some of the results can be directly linked to findings from physiological development, targeting self- and otherconcepts which relate to the views of the self versus the group in individualistic versus collectivistic societies.

Firstly, different self-concepts have been proposed to affect cerebral activation patterns across cultures. On tasks assessing descriptions of the self, the mPFC and the cingulate cortex (CC) have been shown to be more strongly activated in Westerners and (bi-cultural) participants with individualistic traits (Chiao et al., 2009; Chiao et al., 2010). Self-construal priming activated these brain regions culture-dependently as well (Wang, Oyserman, Liu, Li, \& Han, 2013). Judgments of the self versus public figures elicited greater activation in the TPJ in Chinese participants (Ma et al., 2014; Sul, Choi, \& Kang, 2012). In an event-related potential (ERP) study, an advantage of self-recognition over other-recognition has been ascribed to an enhanced self-focused attention of Western participants (Sui, Liu, Wang, \& Han, 2009). Moreover, self-referential thoughts seem to activate different hubs of the resting state network 
on the basis of individualistic versus collectivistic traits (Knyazev, Savostyanov, Volf, Liou, \& Bocharov, 2012).

Secondly, different patterns of emotion recognition across cultures have been proposed to affect cortical activation. An fMRI study showed greater bilateral posterior superior temporal sulci (STS) recruitment during same- versus other-culture mental state decoding in both Japanese and Caucasian-American participants, using the reading-the-mind-in-the-eyes task with Caucasian and Asian stimuli (Adams et al., 2010). In a study using fearful facial stimuli, Japanese participants activated the right IFG, premotor cortex and left insula, while Caucasians activated the posterior CC, supplementary motor cortex and amygdala during task performance (Moriguchi et al., 2005). Authors hypothesized that Caucasians may respond to fearful faces in a more direct, emotional way, while Japanese people do not attach an emotional valence to faces. A study with German and Chinese participants on tolerance toward anger suggested that those with an independent lifestyle activate the right TPJ, right inferior and STS, as well as the left middle insula, while inter-dependent participants activate the left dorsolateral PFC (de Greck et al., 2012). Immordino-Yang studied how cultural effects in automatic neurobiological mechanisms may correspond to differences in the meaning individuals make of the social world and the self (Immordino-Yang, 2013). In one study, the aspect of admiration and compassion in groups of Chinese, Asian-Americans and non-Asian Americans was investigated (Immordino-Yang, Yang, \& Damasio, 2014). Different activation levels in the ventral (Chinese) and dorsal (non-Asians) insula in response to the presentation of videos displaying strength was related to visceral-somatosensory experiences. It was hypothesized that, on the one hand, calmer societies like the Chinese would rather rely on the modulatory role of the ventral insula, gaining insights in the emotionstrength by monitoring somatosensory properties. More active societies like the American, on the other hand, would rather pay attention to the somatosensory feelings gained, conveyed by the dorsal insula.

Intergroup empathy of emotional pain was assessed in Korean and Caucasian participants. Stronger activity in the left TPJ for in-group compared to out-group members was related to stronger empathy and greater preference for social hierarchy (Cheon et al., 2011). Moreover, higher values of other-focusedness were related to activation of the ACC and insula (affective pain matrix) and mPFC in Koreans (Cheon et al., 2013). In a study comparing Arabs, Israelis and South Americans regarding responses to the others' pain and emotional suffering, authors found that, behaviorally, participants reported less empathy towards the respective group they were in conflict with. Contrary to that, functional imaging results indicated less activation of 
the pain matrix and the mentalizing networks when a distant, non-conflict group was involved than in response to the conflict group (Bruneau, Dufour, \& Saxe, 2012). On a ToM task involving biological motion, the mPFC as well as temporal parts of the brain were more strongly activated in Western than in Japanese participants. When autistic features and difficulties to identify feelings were present in Japanese participants, they showed a similar activation pattern to Western participants (Koelkebeck et al., 2011). Lastly, language education was proposed to affect social cognition-related brain activation. Comparing adult American monolinguals and Japanese bilinguals on a ToM task, only the Japanese participants activated the IFG (Kobayashi, Glover, \& Temple, 2006).

To summarize, for its imaging studies in healthy individuals, research has concentrated mainly on the investigation of self- versus other-cognition with a focus on the comparison between Western and East Asian societies. Mostly, findings suggest a culture-dependent activation in brain regions forming parts of specific networks in social cognition, with a stronger activation observed in Western participants. This has been attributed to stronger individualistic traits in Westerners.

\section{Future Research Directions}

The development of early detection tools as well as specific intervention programs to remediate social cognitive deficits is crucial to improving the lives in patients with mental disorders. Cognitive endophenotypes (Gur et al., 2007) can help identify persons at risk and assess therapeutical outcomes. Judging from the results of cross-cultural comparison studies, patient groups display larger deficits, for instance in emotion identification, when stimuli of other cultural contexts are involved (e.g. Habel et al., 2000). In order to create more sophisticated tools assessing mental disorders, a cross-cultural stimulus context may thus be helpful, as this would provide a more sensitive measure than the stimulus sets that are currently used in emotion research.

Other Race Bias (Elfenbein \& Ambady, 2003; Meissner \& Brigham, 2001) suggests that ownrace faces are remembered and discriminated better than other-race faces. Studies have shown that Caucasian individuals make different judgments about facial expressions when targets are either African-American or Caucasian (Hugenberg \& Bodenhausen, 2003) and recognition is faster for positive emotions in Caucasian targets (Hugenberg, 2005). In a study introducing faces of women either covered by a traditional Islamic veil or wearing a cap and scarf a sample of Western European descent recognized fear most quickly when the face was partly hidden by a niqab, while the cap-and-scarf condition was more often associated with 
happiness (Kret \& de Gelder, 2012). Anxiety can lead to more stereotyped emotion attribution (Curtis \& Locke, 2005), which is why tasks employing in-group/out-group stimuli including different race may be helpful in detecting emotion recognition abnormalities in patients with mental disorders which are characterized by high levels of anxiety.

Emotion perception is not only based on facial information (Hunt, 1941) but also on the body and the social context (Kret \& de Gelder, 2010). Research has shown that facial expressions are better recognized when accompanied by a posture and vice versa (Kret, Roelofs, Stekelenburg, \& de Gelder, 2013; Kret, Stekelenburg, Roelofs, \& de Gelder, 2013) and facilitated if expressions are dynamic rather than static (Kilts, Egan, Gideon, Ely, \& Hoffman, 2003; Sato, Kochiyama, Yoshikawa, Naito, \& Matsumura, 2004). In a study on individuals with autism spectrum disorder, patients failed to activate ventral visual areas and the mirror neuron system in response to body postures (Hadjikhani et al., 2009). A recent study showed that gaze avoidance does not necessarily relate to the general avoidance of another person's emotions (Mellings \& Alden, 2000), but that highly socially anxious individuals gain an insight into other people's emotions by attending to alternative information sources, for instance, to expressive hands (Kret, Stekelenburg, de Gelder, \& Roelofs, under review). In another study, violent offenders were investigated who had an attentional bias toward threatening body language rather than toward threatening facial expressions and who misinterpreted bodily expressions as being aggressive (Kret \& de Gelder, 2013). While some studies propose that, e.g., neural responses to race during imitation of gestures and faces are driven by learned associations rather than by self-similarity (Losin, Cross, Iacoboni, \& Dapretto, 2014), the above-mentioned findings suggest that in emotion research the usage of naturalistic stimulus material including the whole body may also open the field for research on neuropsychiatric disorders.

Lastly, while emotion research has predominantly focused on explicit facial expressions in the past (de Gelder et al., 2010), a promising approach for patients with mental disorders might be the investigation of subtle emotion recognition (Burch, 1995; Tsui et al., 2013). The identification of these non-full-strength emotions can be considered to be even more difficult when displayed on a face of a person with a different cultural background (Matsumoto, 1992). Emotion recognition tasks that employ emotional ambiguity in faces with out-group features may therefore have advantages over conventional face recognition paradigms (Koelkebeck et al., 2015; Minoshita et al., 2005).

The outline of tasks that involve emotion identification from (ambiguous) faces with outgroup features and body postures might form the basis of new assessment tools for mental 
disorders. The cultural context of the stimuli might be particularly helpful in targeting deficits, specifically in early intervention. It will be especially helpful to combine behavioral approaches with neuroscientific methods such as fMRI or eye-tracking methods. This might create tools not only to better understand the biological basis of social cognitive deficits in mental disorders, but might also help understand the source of deficits that could be targeted in specific training programs, such as the metacognitive training (Moritz et al., 2014).

\section{Summary}

Rather than viewing culture as a sphere that lies outside of biology, research converges toward the view that human brains evolved to receive and transmit large amounts of cultural information. Cultural viewpoints in psychiatric research are thus essential in refining our understanding of the biological and socio-cultural factors affecting the development and course of diseases that, in turn, influence the onset, development, sustenance and configuration of neuropsychiatric disorders. Psychiatric symptoms in different cultural milieus can inform about the neuroanatomical and functional organization of the brain as the organ (or "acceptor”) of culture. In addition, they might determine optimized diagnostic and intervention methods, answering the question whether it is appropriate to apply the same treatment methods for mental disorders in different cultures (Han et al., 2013; Moritz et al., 2014). While little is known about the influence of culture on social cognition in pathological mental states, recent research has determined neural reaction patterns to social cues that relate to the socio-cultural background of an individual. Culture-based social cognition may impact on the development of tasks assessing social cognition in patient groups utilizing stimulus material encompassing emotional face and body expression. Task designs that involve stimulus material featuring traits of culturally unfamiliar groups might be particularly helpful in this regard. More research is necessary, however, specifically in patient samples. Neurobiological investigation methods might complement these approaches and may also lead to a better understanding of cerebral functioning. Nonetheless, results need to be considered with great care, as other factors may be affecting results of cross-cultural studies. These include differences in health and lifestyles, education, task-dependent effects (Goh et al., 2010) as well as population-specific brain sizes (Knyazev et al., 2012).

\section{Acknowledgements}


Research was supported by a VENI grant (016-155-082) from NWO (Nederlandse $\begin{array}{llll}\text { Organisatie voor } \quad \text { Wetenschappelijk } & \text { Onderzoek) }\end{array}$ 


\section{References}

Adams, R. B.,Jr, Rule, N. O., Franklin, R. G.,Jr, Wang, E., Stevenson, M. T., Yoshikawa, S., . . Ambady, N. (2010). Cross-cultural reading the mind in the eyes: An fMRI investigation. Journal of Cognitive Neuroscience, 22(1), 97-108. doi:10.1162/jocn.2009.21187

Aune, K. S., \& Aune, R. K. (1996). Cultural differences in the self-reported experience and expression of emotions in relationships. Journal of Cross-Cultural Psychology, 27(1), 6781. doi:10.1177/0022022196271005

Bauer, S. M., Schanda, H., Karakula, H., Olajossy-Hilkesberger, L., Rudaleviciene, P., Okribelashvili, N., . . Stompe, T. (2011). Culture and the prevalence of hallucinations in $\begin{array}{llll}\text { schizophrenia. } \quad \text { Comprehensive } & \text { 319-325), }\end{array}$ doi:10.1016/j.comppsych.2010.06.008

Bernieri, F. J., \& Gillis, J. S. (1993). Depressed mood and social perception: A cross-cultural replication. Perceptual and Motor Skills, 77(1), 154. doi:10.2466/pms.1993.77.1.154

Blais, C., Jack, R.E., Scheepers, C., Fiset, D., Caldara, R. (2008). Culture shapes how we look at faces. PLoS ONE, 3, e3022. doi: 10.1371/journal.pone.0003022

Blakemore, S. J., Boyer, P., Pachot-Clouard, M., Meltzoff, A., Segebarth, C., \& Decety, J. (2003). The detection of contingency and animacy from simple animations in the human brain. Cerebral Cortex, 13(8), 837-844. doi:http://dx.doi.org/10.1093/cercor/13.8.837

Brandt, M. E., \& Boucher, J. D. (1985). Judgment of emotions from antecedent situations in three cultures. In I. Lagunes, \& Y. Poortinga (Eds.), From a different perspective: Studies of behavior across cultures (pp. 348-363). Lisse, Netherlands: Swets and Zeitlinger.

Brekke, J. S., Nakagami, E., Kee, K. S., \& Green, M. F. (2005). Cross-ethnic differences in perception of emotion in schizophrenia. Schizophrenia Research, 77(2-3), 289-298. doi:10.1016/j.schres.2005.04.004

Bruneau, E. G., Dufour, N., \& Saxe, R. (2012). Social cognition in members of conflict groups: Behavioural and neural responses in Arabs, Israelis and South Americans to each other's misfortunes. Philosophical Transactions of the Royal Society of London. Series B, Biological Sciences, 367(1589), 717-730. doi:10.1098/rstb.2011.0293 
Burch, J. W. (1995). Typicality range deficit in schizophrenics' recognition of emotion in faces. Journal of Clinical Psychology, 51(2), 140-152. doi:10.1002/10974679(199503)51:2<140::AID-JCLP2270510202>3.0.CO;2-B

Callaghan, T. C., Moll, H., Rakoczy, H., Warneken, F., Liszkowski, U., Behne, T., \& Tomasello, M. (2011). Early social cognition in three cultural contexts. Monographs of the Society for Research in Child Development, 76(2), vii-125. doi:10.1111/j.15405834.2011.00603.x

Castelli, F., Happé, F. G., Frith, U., \& Frith, C. D. (2000). Movement and mind: A functional imaging study of perception and interpretation of complex intentional movement patterns. Neuroimage, 12(3), 314-325. doi:10.1006/nimg.2000.0612

Chen, H., Guarnaccia, P. J., \& Chung, H. (2003). Self-attention as a mediator of cultural influences on depression. The International Journal of Social Psychiatry, 49(3), 192-203. doi:10.1177/00207640030493005

Cheng, S. T. (1996). A critical review of Chinese koro. Culture, Medicine and Psychiatry, 20(1), 67-82. doi:10.1007/BF00118751

Cheon, B. K., Im, D. M., Harada, T., Kim, J. S., Mathur, V. A., Scimeca, J. M., . . Chiao, J. Y. (2013). Cultural modulation of the neural correlates of emotional pain perception: The role of other-focusedness. Neuropsychologia, 51(7), 1177-1186. doi:10.1016/j.neuropsychologia.2013.03.018

Cheon, B. K., Im, D. M., Harada, T., Kim, J. S., Mathur, V. A., Scimeca, J. M., . . Chiao, J. Y. (2011). Cultural influences on neural basis of intergroup empathy. NeuroImage, 57(2), 642-650. doi:10.1016/j.neuroimage.2011.04.031

Chiao, J. Y., Harada, T., Komeda, H., Li, Z., Mano, Y., Saito, D., . . . Iidaka, T. (2009). Neural basis of individualistic and collectivistic views of self. Human Brain Mapping, 30(9), 2813-2820. doi:10.1002/hbm.20707

Chiao, J. Y., Harada, T., Komeda, H., Li, Z., Mano, Y., Saito, D., . . . Iidaka, T. (2010). Dynamic cultural influences on neural representations of the self. Journal of Cognitive Neurosciences, 22(1), 1-11. doi:10.1162/jocn.2009.21192 
Comparelli, A., Corigliano, V., De Carolis, A., Mancinelli, I., Trovini, G., Ottavi, G., . . . Girardi, P. (2013). Emotion recognition impairment is present early and is stable throughout the course of schizophrenia. Schizophrenia Research, 143(1), 65-69. doi:10.1016/j.schres.2012.11.005

Curtis, G. J., \& Locke, V. (2005). The effect of anxiety on impression formation: Affectcongruent or stereotypic biases? The British Journal of Social Psychology, 44(Pt 1), 65-83. doi:10.1348/014466604X23464

de Gelder, B., Van den Stock, J., Meeren, H. K., Sinke, C. B., Kret, M. E., \& Tamietto, M. (2010). Standing up for the body. Recent progress in uncovering the networks involved in the perception of bodies and bodily expressions. Neuroscience and Biobehavioral Reviews, 34(4), 513-527. doi:10.1016/j.neubiorev.2009.10.008

de Greck, M., Shi, Z., Wang, G., Zuo, X., Yang, X., Wang, X., . . . Han, S. (2012). Culture modulates brain activity during empathy with anger. NeuroImage, 59(3), 2871-2882. doi:10.1016/j.neuroimage.2011.09.052

Deeley, Q., Oakley, D. A., Walsh, E., Bell, V., Mehta, M. A., \& Halligan, P. W. (2014). Modelling psychiatric and cultural possession phenomena with suggestion and fMRI. Cortex, 53, 107-119. doi:10.1016/j.cortex.2014.01.004

DeVos, G. (1985). Dimensions of the self in Japanese culture. In A. J. Marsella, G. DeVos \& F. L. K. Hsu (Eds.), Culture and self: Asian and western perspectives (pp. 141-184). New York: Tavistock. doi:10.1525/ae.1986.13.4.02a00180

Ekman, P., \& Friesen, W. V. (1971). Constants across cultures in the face and emotion. Journal of Personality and Social Psychology, 17(2), 124-129. doi:http://dx.doi.org/10.1037/h0030377

Ekman, P., Friesen, W. V., \& Ellsworth, P. (1972). Emotion in the human face: Guidelines for research and an interaction of findings. New York: Pergamon Press.

Elfenbein, H., \& Ambady, N. (2003). Universals and cultural differences in recognizing emotions. Current Directions in Psychological Science, 12(5), 159-164. doi:10.1111/14678721.01252 
Fabrega, H.,Jr. (1989). The self and schizophrenia: A cultural perspective. Schizophrenia Bulletin, 15(2), 277-290. doi:10.1093/schbul/15.2.277

Freudenmann, R. W., \& Schonfeldt-Lecuona, C. (2005). Das Syndrom der genitalen Retraktion aus Sicht der transkulturellen Psychiatrie. Chinesisches Suo yang, indonesisches Koro und nichtasiatische Formen (Koro-aehnliche Symptome). [The syndrome of genital retraction from a transcultural psychiatric point of view. Chinese suo yang, Indonesian koro and non-Asian forms (koro-like symptoms)]. Der Nervenarzt, 76(5), 569-580. doi:10.1007/s00115-004-1822-4

Furukawa, F., \& Bourgeois, M. (1984). Delusions of possession by the fox in Japan (or kitsune-tsuki delusion). [Delires de possession par le renard au Japon (ou delire de Kitsune-Tsuki)] Annales Medico-Psychologiques, 142(5), 677-687. doi:http://psycnet.apa.org/psycinfo/1985-22698-001

Gecici, O., Kuloglu, M., Guler, O., Ozbulut, O., Kurt, E., Onen, S., . . A Albayrak, Y. (2010). Phenomenology of delusions and hallucinations in patients with schizophrenia. Bulletin of Clinical Psychopharmacology, 204-212. doi:http://www.psikofarmakoloji.org/pdf/20_3_3.pdf

Gillis, J. S., \& Bernieri, F. J. (1993). Effects of depressed mood on social perception. Perceptual and Motor Skills, 76(2), 674. doi:10.2466/pms.1993.76.2.674

Goh, J. O., Leshikar, E. D., Sutton, B. P., Tan, J. C., Sim, S. K., Hebrank, A. C., \& Park, D. C. (2010). Culture differences in neural processing of faces and houses in the ventral visual cortex. Social Cognitive and Affective Neuroscience, 5(2-3), 227-235. doi:10.1093/scan/nsq060

Gur, R. E., Calkins, M. E., Gur, R. C., Horan, W. P., Nuechterlein, K. H., Seidman, L. J., \& Stone, W. S. (2007). The consortium on the genetics of schizophrenia: Neurocognitive endophenotypes. Schizophrenia Bulletin, 33(1), 49-68. doi:sbl055

Habel, U., Gur, R. C., Mandal, M. K., Salloum, J. B., Gur, R. E., \& Schneider, F. (2000). Emotional processing in schizophrenia across cultures: Standardized measures of discrimination and experience. Schizophrenia Research, 42(1), 57-66. doi:10.1016/S09209964(99)00093-6 
Hadjikhani, N., Joseph, R. M., Manoach, D. S., Naik, P., Snyder, J., Dominick, K., . . . de Gelder, B. (2009). Body expressions of emotion do not trigger fear contagion in autism spectrum disorder. Social Cognitive and Affective Neuroscience, 4(1), 70-78. doi:10.1093/scan/nsn038

Han, S., Northoff, G., Vogeley, K., Wexler, B. E., Kitayama, S., \& Varnum, M. E. (2013). A cultural neuroscience approach to the biosocial nature of the human brain. Annual Review of Psychology, 64, 335-359. doi:10.1146/annurev-psych-071112-054629

Hendry, J. (1986). Becoming Japanese: The world of the pre-school child. Manchester, UK: Manchester University Press.

Hoertnagl, C.M., Hofer, A. (2014). Social cognition in serious mental illness. Curr Opin Psychiatry, 27(3), 197-202. doi: 10.1097/YCO.0000000000000055

Hugenberg, K. (2005). Social categorization and the perception of facial affect: Target race moderates the response latency advantage for happy faces. Emotion (Washington, D.C.), 5(3), 267-276. doi:10.1037/1528-3542.5.3.267

Hugenberg, K., \& Bodenhausen, G. V. (2003). Facing prejudice: Implicit prejudice and the perception of facial threat. Psychological Science, 14(6), 640-643. doi:10.1046/j.09567976.2003.psci_1478.x

Hunt, W. A. (1941). Recent developments in the field of emotion. Psychological Bulletin, 38, 249-276. doi:http://dx.doi.org/10.1037/h0093573

Immordino-Yang, M. H. (2013). Studying the effects of culture by integrating neuroscientific with ethnographic approaches. Psychological Inquiry, 24, 42-46. doi:10.1080/1047840X.2013.770278

Immordino-Yang, M. H., Yang, X. F., \& Damasio, H. (2014). Correlations between socialemotional feelings and anterior insula activity are independent from visceral states but influenced by culture. Frontiers in Human Neuroscience, 8, 728. doi:10.3389/fnhum.2014.00728

Jablensky, A., Sartorius, N., Gulbinat, W., \& Ernberg, G. (1981). Characteristics of depressive patients contacting psychiatric services in four cultures. A report from the who 
collaborative study on the assessment of depressive disorders. Acta Psychiatrica Scandinavica, 63(4), 367-383. doi:http://dx.doi.org/10.1111/j.1600-0447.1981.tb00685.x

Jilek, W. G. (1995). Emil Kraepelin and comparative sociocultural psychiatry. European Archives of Psychiatry and Clinical Neuroscience, 245(4-5), 231-238. doi: 10.1007/BF02191802

Kato, T. A., Shinfuku, N., Sartorius, N., \& Kanba, S. (2011). Are Japan’s hikikomori and depression in young people spreading abroad? Lancet, 378(9796). doi:10.1016/S01406736(11)61475-X

Kilts, C. D., Egan, G., Gideon, D. A., Ely, T. D., \& Hoffman, J. M. (2003). Dissociable neural pathways are involved in the recognition of emotion in static and dynamic facial expressions. NeuroImage, 18(1), 156-168. doi:S1053811902913236

Kim, K., Hwu, H., Zhang, L. D., Lu, M. K., Park, K. K., Hwang, T. J., . . Park, Y. C. (2001). Schizophrenic delusions in Seoul, Shanghai and Taipei: A transcultural study. Journal of Korean Medical Science, 16(1), 88-94. doi:http://dx.doi.org/10.3346/jkms.2001.16.1.88

Kim, K. I., Li, D., Jiang, Z., Cui, X., Lin, L., Kang, J. J., . . . Kim, C. K. (1993). Schizophrenic delusions among Koreans, Korean-Chinese and Chinese: A transcultural study. The International Journal of Social Psychiatry, 39(3), 190-199. doi:10.1177/002076409303900305

Kirmayer, L. J., \& Groleau, D. (2001). Affective disorders in cultural context. Cultural Psychiatry: International Perspectives, 24(3), 465-478. doi:10.1016/S0193953X(05)70241-0

Kirmayer, L. J. (2001). Cultural variations in the clinical presentation of depression and anxiety: Implications for diagnosis and treatment. The Journal of Clinical Psychiatry, 62 Suppl 13, 22-8; discussion 29-30.

Kirov, G., \& Murray, R. M. (1999). Ethnic differences in the presentation of bipolar affective disorder. European Psychiatry, 14(4), 199-204. doi:S0924933899807421 
Kitayama, S., Duffy, S., Kawamura, T., \& Larsen, J. T. (2003). Perceiving an object and its context in different cultures: A cultural look at new look. Psychological Science, 14(3), 201-206. doi:10.1111/1467-9280.02432

Kleinman, A. M., \& Good, B. (1985). Culture and depression. Berkeley, CA: University of California Press.

Knyazev, G. G., Savostyanov, A. N., Volf, N. V., Liou, M., \& Bocharov, A. V. (2012). EEG correlates of spontaneous self-referential thoughts: A cross-cultural study. International Journal of Psychophysiology, 86(2), 173-181. doi:10.1016/j.ijpsycho.2012.09.002

Kobayashi, F. C., Glover, G. H., \& Temple, E. (2006). Cultural and linguistic influence on neural bases of 'theory of mind': An fMRI study with Japanese bilinguals. Brain and Language, 98(2), 210-220. doi:10.1016/j.bandl.2006.04.013

Kobayashi, F. C., Glover, G. H., \& Temple, E. (2007). Cultural and linguistic effects on neural bases of 'Theory of Mind' in American and Japanese children. Brain Research, 1164, 95-107. doi:10.1016/j.brainres.2007.06.022

Koelkebeck, K., Kohl, W., Luettgenau, J., Triantafillou, S., Ohrmann, P., Satoh, S., \& Minoshita, S. (2015). Benefits of using stimuli with culturally unfamiliar features in ambiguous emotion identification: A cross-cultural study. Psychiatry Research, 228(1), 3945. doi: 10.1016/j.psychres.2015.04.005

Koelkebeck, K., \& Wilhelm, C. (2014). Cross-cultural aspects of social cognitive abilities in schizophrenia. In P. H. Lysaker, G. Dimaggio \& M. Bruene (Eds.), Social cognition and metacognition in schizophrenia: Psychopathology and treatment approaches (pp. 29-47). London, Waltham, San Diego: Elsevier. doi: http://dx.doi.org/10.1016/B978-0-12-405172$0.00001-6$

Koelkebeck, K., Hirao, K., Kawada, R., Miyata, J., Saze, T., Ubukata, S., . . . Murai, T. (2011). Transcultural differences in brain activation patterns during theory of mind (ToM) task performance in Japanese and Caucasian participants. Social Neuroscience, 6(5-6), 615-626. doi:10.1080/17470919.2011.620763 
Kondo, N., Sakai, M., Kuroda, Y., Kiyota, Y., Kitabata, Y., \& Kurosawa, M. (2013). General condition of hikikomori (prolonged social withdrawal) in japan: Psychiatric diagnosis and outcome in mental health welfare centres. The International Journal of Social Psychiatry, 59(1), 79-86. doi:10.1177/0020764011423611

Kret, M. E., Stekelenburg, J. J., de Gelder, B., \& Roelofs, K. (under review). From face to hand: Attentional bias towards expressive hands in social anxiety.

Kret, M. E., \& de Gelder, B. (2010). Social context influences recognition of bodily expressions. Experimental Brain Research, 203(1), 169-180. doi:10.1007/s00221-0102220-8

Kret, M. E., \& de Gelder, B. (2012). Islamic headdress influences how emotion is recognized from the eyes. Frontiers in Psychology, 3, 110. doi:10.3389/fpsyg.2012.00110

Kret, M. E., \& de Gelder, B. (2013). When a smile becomes a fist: The perception of facial and bodily expressions of emotion in violent offenders. Experimental Brain Research, 228(4), 399-410. doi:10.1007/s00221-013-3557-6

Kret, M. E., Roelofs, K., Stekelenburg, J. J., \& de Gelder, B. (2013). Emotional signals from faces, bodies and scenes influence observers' face expressions, fixations and pupil-size. Frontiers in Human Neuroscience, 7, 810. doi:10.3389/fnhum.2013.00810

Kret, M. E., Stekelenburg, J. J., Roelofs, K., \& de Gelder, B. (2013). Perception of face and body expressions using electromyography, pupillometry and gaze measures. Frontiers in Psychology, 4, 28. doi:10.3389/fpsyg.2013.00028

Lee, K., Olson, D. R., \& Torrance, N. (1999). Chinese children's understanding of false beliefs: The role of language. Journal of Child Language, 26(1), 1-21. doi:10.1017/S0305000998003626

Lee, S. J., Lee, H. K., Kweon, Y. S., Lee, C. T., \& Lee, K. U. (2010). Deficits in facial emotion recognition in schizophrenia: A replication study with Korean subjects. Psychiatry Investigation, 7(4), 291-297. doi:10.4306/pi.2010.7.4.291 
Li, H., \& Rao, N. (2000). Parental influences on Chinese literacy development: A comparison of preschoolers in Beijing, Hong Kong and Singapore. International Journal of Behavioral Development, 24, 82-90. doi:10.1080/016502500383502

Lieberman, M. D. (2007). Social cognitive neuroscience: A review of core processes. Annual Review of Psychology, 58, 259-289. doi:10.1146/annurev.psych.58.110405.085654

Losin, E. A., Cross, K. A., Iacoboni, M., \& Dapretto, M. (2014). Neural processing of race during imitation: Self-similarity versus social status. Human Brain Mapping, 35(4), 17231739. doi:10.1002/hbm.22287

Ma, Y., Bang, D., Wang, C., Allen, M., Frith, C., Roepstorff, A., \& Han, S. (2014). Sociocultural patterning of neural activity during self-reflection. Social Cognitive and Affective Neuroscience, 9(1), 73-80. doi:10.1093/scan/nss103

Ma, Y., Wang, C., Li, B., Zhang, W., Rao, Y., \& Han, S. (2014). Does self-construal predict activity in the social brain network? A genetic moderation effect. Social Cognitive and Affective Neuroscience, 9(9), 1360-1367. doi:10.1093/scan/nst125

Markham, R., \& Wang, L. (1996). Recognition of emotion by Chinese and Australian children. Journal of Cross-Cultural Psychology, 27(5), 616-643. doi:10.1177/0022022196275008

Markus, H. R., \& Kitayama, S. (1991). Culture and the self: Implications for cognition, emotion, and motivation. Psychological Review, 98, 224-253. doi:http://dx.doi.org/10.1037/0033-295X.98.2.224

Marsella, A. J. (1980). Depressive experience and disorder across cultures. In H. C. Triandis, \& J. G. Draguns (Eds.), Handbook of transcultural psychology (pp. 233-262). Boston, MA: Allyn and Bacon.

Matsuda, T., \& Nisbett, R. E. (2001). Attending holistically versus analytically: Comparing the context sensitivity of Japanese and Americans. Journal of Personality and Social Psychology, 81(5), 922-934. doi:10.1037/0022-3514.81.5.922 
Matsumoto, D. (1992). American-Japanese cultural differences in the recognition of universal facial expressions. Journal of Cross Cultural Psychology, 23, 72-84. doi:10.1177/0022022192231005

Matsumoto, D., \& Ekman, P. (1989). American-Japanese cultural differences in intensity ratings of facial expressions of emotion. Motivation and Emotion, 13(2), 143-157. doi:10.1007/BF00992959

Matsumoto, D., LeRoux, J., Wilson-Cohn, C., Raroque, J., Kooken, K., Ekman, P., . . Goh, A. (2000). A new test to measure emotion recognition ability: Matsumoto and Ekman's Japanese and Caucasian brief affect recognition test (JACBART). Journal of Nonverbal Behavior, 24(3), 179-209. doi:http://link.springer.com/search?query=matsumoto\&searchwithin=Journal\&facet-journal-id=10919

McHugh, P. R., \& Slavney, P. R. (1998). The perspectives of psychiatry (2 ${ }^{\text {nd }}$ edition). Baltimore and London: Johns Hopkins University Press.

McLean, D., Thara, R., John, S., Barrett, R., Loa, P., McGrath, J., Mowry, B. (2014). DSMIV "criterion A" schizophrenia symptoms across ethnically different populations: evidence for differing psychotic symptom content or structural organization? Culture, Medicine, and Psychiatry, 38(3), 408-426. doi:10.1007/s11013-014-9385-8.

Meissner, C. A., \& Brigham, J. C. (2001). Thirty years of investigating the own-race bias in memory for faces: A meta-analytic review. Psychology, Public Policy, and Law, 7(1), 335. doi:10.1037//1076-8971.7.1.3

Mellings, T. M., \& Alden, L. E. (2000). Cognitive processes in social anxiety: The effects of self-focus, rumination and anticipatory processing. Behaviour Research and Therapy, 38(3), 243-257. doi:S0005-7967(99)00040-6.

Mesulam, M. M. (1981). Dissociative states with abnormal temporal lobe EEG. Multiple personality and the illusion of possession. Archives of Neurology, 38(3), 176-181. doi:10.1001/archneur.1981.00510030070010

Minoshita, S., Morita, N., Yamashita, T., Yoshikawa, M., Kikuchi, T., \& Satoh, S. (2005). Recognition of affect in facial expression using the Noh mask test: Comparison of 
individuals with schizophrenia and normal controls. Psychiatry and Clinical Neurosciences, 59(1), 4-10. doi:10.1111/j.1440-1819.2005.01325.x

Minsky, S., Vega, W., Miskimen, T., Gara, M., \& Escobar, J. (2003). Diagnostic patterns in Latino, African American, and European American psychiatric patients. Archives of General Psychiatry, 60(6), 637-644. doi:10.1001/archpsyc.60.6.637

Moriguchi, Y., Ohnishi, T., Kawachi, T., Mori, T., Hirakata, M., Yamada, M., .. . Komaki, G. (2005). Specific brain activation in Japanese and Caucasian people to fearful faces. Neuroreport, 16(2), 1

Moritz, S., Andreou, C., Schneider, B.C., Wittekind, C.E., Menon, M., Balzan, R.P., Woodward, T.S. (2014). Sowing the seeds of doubt: a narrative review on metacognitive training in schizophrenia. Clinical Psychology Review, 34(4), 358-366. doi: 10.1016/j.cpr.2014.04.004

Murphy, J. M. (1976). Psychiatric labeling in cross-cultural perspective. Science, 191(4231), 1019-1028. doi:http://dx.doi.org/10.1097/00001756-200502080-00012

Naito, M., \& Koyama, K. (2006). The development of false-belief understanding in Japanese children: Delay and difference? International Journal of Behavioral Development, 30 (4), 290-304. doi:10.1177/0165025406063622

Ndetei, D. M., \& Vadher, A. (1984). A comparative cross-cultural study of the frequencies of hallucination in schizophrenia. Acta Psychiatrica Scandinavica, 70(6), 545-549. doi:10.1111/j.1600-0447.1984.tb01247.x.

Omata, W. (1985). Schizoaffektive Psychosen in Deutschland und in Japan--Eine transkulturell-psychiatrische Studie. [Schizoaffective psychoses in Germany and Japan--a transcultural psychiatric study]. Fortschritte der Neurologie-Psychiatrie, 53(5), 168-176. doi:10.1055/s-2007-1001964

Perris, C., Eisemann, M., Eriksson, U., Perris, H., Kemali, D., Amati, A., . . . Vacca, L. (1981). Transcultural aspects of depressive symptomatology. Psychiatria Clinica, 14(2), 69-80. doi:10.1159/000283904 
Pinkham, A. E., Sasson, N. J., Calkins, M. E., Richard, J., Hughett, P., Gur, R. E., \& Gur, R. C. (2008). The other-race effect in face processing among African American and Caucasian individuals with schizophrenia. The American Journal of Psychiatry, 165(5), 639-645. doi:10.1176/appi.ajp.2007.07101604

Richerson, P. J., \& Boyd, R. (2005). Not by genes alone: How culture transformed human evolution. Chicago: University of Chicago Press. doi:10.1007/s10818-008-9031-z

Sass, L. A. (1997). The consciousness machine: Self and subjectivity and schizophrenia and modern culture. In U. Neisser, \& D. A. Jopling (Eds.), The conceptual self in context: Culture, experience, self-understanding (pp. 203-230). Cambridge: Cambridge University Press.

Sato, W., Kochiyama, T., Yoshikawa, S., Naito, E., \& Matsumura, M. (2004). Enhanced neural activity in response to dynamic facial expressions of emotion: An fMRI study. Brain Research. Cognitive Brain Research, 20(1), 81-91. doi:10.1016/j.cogbrainres.2004.01.008

Shweder, R. A., Goodnow, J., Hatano, G., LeVine, R. A., Markus, H., \& Miller, P. (1998). The cultural psychology of development: One mind, many mentalities. In W. Damon, \& R. M. Lerner (Eds.), Handbook of child psychology: Theoretical models of human development (5th Ed ed., pp. 865-937). New York, USA: John Wiley \& Sons.

Siegert, R. J. (2001). Culture, cognition, and schizophrenia. In J. S. Schumaker, \& T. Ward (Eds.), Cultural cognition and psychopathology (pp. 171-189). Westport, Connecticut: Praeger.

Singh, S. P., Harley, K., \& Suhail, K. (2013). Cultural specificity of emotional overinvolvement: A systematic review. Schizophrenia Bulletin, 39(2), 449-463. doi:10.1093/schbul/sbr170

Stompe, T., Friedman, A., Ortwein, G., Strobl, R., Chaudhry, H. R., Najam, N., \& Chaudhry, M. R. (1999). Comparison of delusions among schizophrenics in Austria and in Pakistan. Psychopathology, 32(5), 225-234. doi:29094 
Suhail, K., \& Cochrane, R. (2002). Effect of culture and environment on the phenomenology of delusions and hallucinations. The International Journal of Social Psychiatry, 48(2), 126138. doi:10.1177/002076402128783181

Sui, J., Liu, C. H., Wang, L., \& Han, S. (2009). Attentional orientation induced by temporarily established self-referential cues. Quarterly Journal of Experimental Psychology, 62(5), 844-849. doi:10.1080/17470210802559393

Sul, S., Choi, I., \& Kang, P. (2012). Cultural modulation of self-referential brain activity for personality traits and social identities. Social Neuroscience, 7(3), 280-291. doi:10.1080/17470919.2011.614001

Sumathipala, A., Siribaddana, S. H., \& Bhugra, D. (2004). Culture-bound syndromes: The story of Dhat syndrome. The British Journal of Psychiatry, 184, 200-209. doi:10.1192/bjp.184.3.200

Suzuki, K., Takei, N., Kawai, M., Minabe, Y., \& Mori, N. (2003). Is taijin kyofusho a culturebound syndrome? The American Journal of Psychiatry, 160(7), 1358. doi:http://dx.doi.org/10.1176/appi.ajp.160.7.1358

Tateyama, M., Asai, M., Hashimoto, M., Bartels, M., \& Kasper, S. (1998). Transcultural study of schizophrenic delusions. Tokyo versus Vienna and Tuebingen (Germany). Psychopathology, 31(2), 59-68. doi:10.1159/000029025

Tateyama, M., Asai, M., Kamisada, M., Hashimoto, M., Bartels, M., \& Heimann, H. (1993). Comparison of schizophrenic delusions between Japan and Germany. Psychopathology, 26(3-4), 151-158. doi:10.1159/000284815

Teo, A. R., \& Gaw, A. C. (2010). Hikikomori, a Japanese culture-bound syndrome of social withdrawal? A proposal for DSM-5. The Journal of Nervous and Mental Disease, 198(6), 444-449. doi:10.1097/NMD.0b013e3181e086b1

Tomasello, M. (2000). The cultural origins of human cognition. Cambridge, MA: Harvard University Press.

Triandis, H. C. (2001). Individualism-collectivism and personality. Journal of Personality, 69(6), 907-924. doi:10.1111/1467-6494.696169 
Tsui, C. F., Huang, J., Lui, S. S., Au, A. C., Leung, M. M., Cheung, E. F., \& Chan, R. C. (2013). Facial emotion perception abnormality in patients with early schizophrenia. Schizophrenia Research, 147(2-3), 230-235. doi:10.1016/j.schres.2013.04.019

van Praag, H. M. (1990). Two-tier diagnosing in psychiatry. Psychiatry Research, 34(1), 1-11. doi:0165-1781(90)90053-8

Veling, W., Hoek, H. W., Selten, J. P., \& Susser, E. (2011). Age at migration and future risk of psychotic disorders among immigrants in the Netherlands: A 7-year incidence study. The American Journal of Psychiatry, 168(12), 1278-1285. doi:10.1176/appi.ajp.2011.11010110

Voellm, B. A., Taylor, A. N., Richardson, P., Corcoran, R., Stirling, J., McKie, S., . . Elliott, R. (2006). Neuronal correlates of theory of mind and empathy: A functional magnetic resonance imaging study in a nonverbal task. Neuroimage, 29(1), 90-98. doi:10.1016/j.neuroimage.2005.07.022

Wang, C., Oyserman, D., Liu, Q., Li, H., \& Han, S. (2013). Accessible cultural mind-set modulates default mode activity: Evidence for the culturally situated brain. Social Neuroscience, 8(3), 203-216. doi:10.1080/17470919.2013.775966

Weissman, M. M., Bland, R. C., Canino, G. J., Faravelli, C., Greenwald, S., Hwu, H. G., . . . Yeh, E. K. (1996). Cross-national epidemiology of major depression and bipolar disorder. JAMA, 276(4), 293-299. doi:10.1001/jama.1996.03540040037030

Wellman, H. M., Cross, D., \& Watson, J. (2001). Meta-analysis of theory-of-mind development: The truth about false belief. Child Development, 72(3), 655-684. doi:10.1111/1467-8624.00304

Wellman, H. M., Fang, F., Liu, D., Zhu, L., \& Liu, G. (2006). Scaling of theory-of-mind understandings in Chinese children. Psychological Science, 17(12), 1075-1081. doi: PSCI1830 [pii] 10.1111/j.1467-9280.2006.01830.x

Yap, P. M. (1951). Mental diseases peculiar to certain cultures: A survey of comparative psychiatry. The Journal of Mental Science, 97(407), 313-327. doi:10.1192/bjp.97.407.313 